\title{
CONCEPÇÕES TEÓRICAS E VERIFICAÇÕES EMPÍRICAS SOBRE A COOPERAÇÃO ENTRE FIRMAS NO BRASIL: UMA INTRODUÇÃO AO FÓRUM ALIANÇAS ESTRATÉGICAS E REDES DE ALIANÇAS
}

Há exatamente dez anos, um grupo de pesquisadores dedicou-se a compreender a emergência do fenômeno da cooperação entre firmas por meio de alianças e redes. Combinando lentes teóricas diversas e estudando diferentes iniciativas organizaram uma das primeiras publicações brasileiras a tratar especificamente do tema (Verschoore, 2004a). Naquele momento, a cooperação entre firmas despontava como uma alternativa estratégica perante as transformações socioeconômicas que estavam em marcha desde o final do século XX. Alianças e redes se formavam para lidar com as pressões oriundas da expansão internacional da concorrência, da aceleração dos avanços tecnológicos, do aumento da conectividade, e, sobretudo, para lidar com clientes mais bem informados e qualificados para tomar decisões de compra. Como decorrência, as preocupações acadêmicas estavam centradas em entender os antecedentes que motivavam a cooperação, os mecanismos que possibilitavam estabelecer os relacionamentos entre firmas e os consequentes resultados da ação conjunta (Borgatti \& Foster, 2003).

No Brasil, os estudos acerca do tema começavam a florescer. Os resultados se refletiam na expansão da publicação de artigos em periódicos científicos por volta do ano de 2004. Em sua maioria, procuravam enriquecer o conhecimento sobre o tema da cooperação em alianças e redes a partir da própria trajetória acadêmica nacional na área das ciências sociais e, em especial, na administração. A primeira década do século XXI reúne, portanto, um conjunto de estudos que estabelecem contribuições teóricas e verificações empíricas essencialmente brasileiras ao tema (Verschoore, 2004b). Embora nenhuma lista seja exaustiva e consiga incluir todo o conhecimento gerado naquele período, é importante resgatar algumas dessas contribuições e verificações que ajudaram a estabelecer esse campo de estudo no Brasil. 
No que tange às contribuições teóricas ao tema, a academia brasileira incorporou discussões variadas e complementares que bem representam a multiplicidade de olhares que a caracteriza. Laniado e Baiardi (2003), por exemplo, estudaram a cooperação entre firmas na Bahia e identificaram diferentes fatores e atores que influenciavam a formação de redes, os objetivos almejados e os resultados alcançados. Balestrin e Vargas (2004), em uma ênfase orientada pela estratégia cooperativa, aperfeiçoaram um mapa conceitual para compreender a diversidade de tipos de alianças e redes de alianças entre a formalidade e a informalidade, e entre a decisão centralizada e descentralizada. Sacomano Neto e Truzzi (2004) realçaram os aspectos relacionais e estruturais das redes e de sua governança. Lopes e Baldi (2005), por sua vez, enriqueceram o debate trazendo à tona os fatores socioculturais e a imersão social dos relacionamentos para explicar a formação dos arranjos de cooperação entre firmas. Segatto-Mendes e Rocha (2005) incorporaram a riqueza da teoria da agência para estudar os processos de cooperação. No mesmo ano, Pereira e Pedrozo (2005) direcionaram o foco de análise para a firma no intuito de entender como os relacionamentos em rede surgem, aprendem e se desenvolvem.

As verificações empíricas também demonstraram a rica diversidade das formas de cooperação entre firmas no Brasil. Os estudos empíricos realizados naquele período evidenciaram o surgimento de iniciativas de redes entre fornecedores da cadeia de suprimento da indústria do petróleo (Balestro, Antunes, Lopes, $\&$ Pellegrin, 2004), de redes associativas entre firmas de pequeno porte do ramo varejista (Böhe \& Silva, 2004; Pereira, 2004) e de fabricantes de móveis (Macadar, 2004). Com o mesmo foco nas firmas de pequeno porte, foram estudados os consórcios de exportação no ramo de confecções (Kushima \& Bulgacov, 2006) e verificadas, empiricamente, as relações interorganizacionais entre 40 produtores agroindustriais do município de Videira, em Santa Catarina (Machado-da-Silva \& Coser, 2006). Não obstante, durante o período em pauta, analisaram-se também as alianças estratégicas da Companhia Vale do Rio Doce (Tauhata \& Macedo-Soares, 2004), as constelações nos serviços de transporte aéreo (Lazzarini \& Joaquim, 2004), as iniciativas de cooperação tecnológica com universidades no setor energético (Segatto-Mendes \& Mendes, 2006), entre outros exemplos.

Uma década talvez não seja tempo suficiente para uma análise retrospectiva plena, mas esse espaço de tempo pode ser capaz de proporcionar avanços significativos no conhecimento sobre um tema. No caso do campo de estudo sobre cooperação entre firmas, os últimos dez anos foram profícuos para seu amadurecimento teórico e empírico. No âmbito nacional, a análise bibliométrica dos estudos sobre cooperação feita por Balestrin, Verschoore e Reyes (20I0) apontou interesses direcionados aos resultados de aprendizagem e de inovação e uma base conceitual predominantemente sustentada por estratégia, dependência de 
recursos, redes sociais e teoria institucional. No âmbito internacional, os estudos têm enriquecido o conhecimento sobre as diferentes abordagens que explicam os relacionamentos cooperativos, tais como as perspectivas evolucionárias, críticas, políticas, psicológicas e sociais, além de avançarem na compreensão dos aspectos que afetam sua ocorrência, como confiança, capital social, poder, temporalidade e mudança (Cropper, Ebers, Huxham, \& Ring, 20I4).

Nesse contexto, desponta a oportunidade para realizar uma recapitulação dos avanços recentes sobre o tema. O propósito do fórum especial sobre alianças e redes de alianças da Revista de Administração Mackenzie (RAM) foi compor um novo panorama das contribuições teóricas e das verificações empíricas sobre a cooperação entre firmas. Para tanto, foi feito um convite à comunidade acadêmica para contribuir com os resultados de seus estudos, na forma de trabalhos teóricos ou teórico-empíricos. Ao todo, foram recebidos 38 manuscritos, os quais envolveram 37 pareceristas em um processo de avaliação que durou seis meses. Os seis artigos publicados neste fórum especial refletem a diversidade de perspectivas teóricas, abordagens metodológicas e fenômenos cooperativos, coerente com a já mencionada trajetória da pesquisa nacional. Caracterizam, assim, uma amostragem da atual produção brasileira sobre o tema cooperação em alianças e redes.

O fórum especial sobre alianças estratégicas e redes de alianças se propôs a reunir um conjunto representativo das recentes concepções teóricas e das novas verificações empíricas de pesquisadores brasileiros sobre o fenômeno da cooperação entre firmas. O resultado deste esforço acadêmico materializa-se nos artigos que compõem esta seção especial. A heterogeneidade das seis contribuições publicadas não apenas demonstra a riqueza das pesquisas sobre o tema no Brasil como também amplia as possibilidades de estudos futuros aos autores, que já trafegam pelos caminhos da cooperação alianças e redes de alianças, e àqueles que agora se integram ao campo.

Neste fórum especial, o artigo "A confiança em situações ambivalentes e incongruentes: a utilização de vinhetas como método exploratório", de Charles Kirschbaum e de José Carlos Hoelz, tem como alicerce teórico as diferentes abordagens da confiança e busca compreender como atores interpretam as situações nas quais há ambivalência nas características relacionais dos parceiros. Para tanto, realizam um estudo qualitativo e exploratório, adotando o uso de vinhetas como mecanismo para acessar o repertório de narrativas dos entrevistados. O estudo, realizado em uma organização produtora de software e de soluções de TI, identifica quatro mecanismos utilizados pelos indivíduos para dar "fechamento" às situações relacionais e demonstram que a adoção de um mecanismo em detrimento a outro pode ter implicações importantes para o desdobramento das relações entre firmas. 
O principal objetivo do artigo "Embeddedness Estrutural e Espacial em Redes Estratégicas: Efeitos Atitudinais no Nível das Díades” de Cristiano Oliveira-Maciel, Marinês Taffarel e Camila Camargo, é dimensionar os efeitos da imersão estrutural e espacial sobre a similaridade atitudinal dos agentes do APL de malhas em Imbituva, Paraná. Utilizando uma survey sociométrica foram coletados dados relacionais da rede e os atributos das características pessoais e das atitudes das 25 firmas participantes. A análise das 600 díades geradas apontou que os efeitos da imersão estrutural e espacial são diferentes para relações de natureza afetiva e cognitiva e que a proximidade geográfica entre as firmas leva uma similaridade na avaliação de desempenho da coordenação da rede.

O texto de autoria de Fábio Vizeu, Edson Ronaldo Guarido Filho e Marcelo Alves Gomes, "Para Além do Olhar Econômico nas Alianças Estratégicas: Implicações Sociológicas do Caso Unihotéis” se propõe a discutir o fenômeno das alianças estratégicas à luz da perspectiva sociológica. O estudo combinou os métodos da história oral e da entrevista semi-estruturada, envolvendo 2I representantes do Sebrae, Senac, Sindhotéis e dos hoteleiros da rede Unihotéis. Entre as contribuições e implicações do caso abordado, destacam-se o reconhecimento de que o processo de formação de alianças estratégicas configura-se como uma arena política com a relevância de aspectos simbólicos na constituição das relações entre os parceiros. Os resultados do estudo apontaram a influência dos princípios e dos valores que orientam ações e papéis na rede, que remete à dimensão ideacional dos relacionamentos. Neste sentido, as alianças estratégicas não podem ser concebidas à luz de arranjos contratuais, pois a adesão dos parceiros depende também das referências sociais que atribuem valor e reconhecimento social, constituindo as bases para a legitimidade organizacional. Com base nos resultados, os autores elaboraram quatro proposições que podem servir como orientação para futuros estudos.

Daniele Lourdes Curto da Costa Martins e José Paulo de Souza são autores de "Atributos da transação e mensuração e sua influência nas relações entre cooperados e cooperativas em sistemas agroindustriais suinícolas". Esse artigo utilizou como base de análise as abordagens dos custos de transação e dos custos de mensuração, com isso buscou compreender como os atributos da transação e da mensuração influenciam as relações entre produtores e processadores suinícolas da região oeste do Paraná. Por meio de um estudo qualitativo em duas organizações cooperativas, os autores observaram atributos vinculados aos custos de transação e de mensuração como a racionalidade limitada, o oportunismo e a especificidade de ativos. A estrutura de governança híbrida encontrada baseia-se em contratos formais e informais que desempenham dois papéis. Por um lado, eles servem como mecanismo para equilibrar a relação entre cooperativa 
e produtores. Por outro, servem como mecanismo para manter a fidelidade do produtor com a organização cooperativa.

O objeto de estudo do artigo de Edson Antunes Quaresma Júnior, Everton Rodrigues Silva e Alexandre de Pádua Carrieri, é uma organização muitas vezes negligenciada pela Administração: as organizações circenses. "As alianças estratégicas no picadeiro da arte/negócio circense" propõe estudar a contribuição das alianças para a longevidade das firmas alicerçado em uma abordagem qualitativa de três circos de grande porte da região sudeste do Brasil. Os resultados encontrados pelos autores demonstram que as alianças são fonte de valor às firmas ao proporcionar melhorias de desempenho nas três dimensões analisadas: econômica, diferenciação competitiva e capacidade adaptativa. Com base nas evidências, os autores apontam possibilidades de pesquisas que aprofundem aspectos como a fluidez e a extensão dos limites organizacionais, os jogos de poder entre as partes envolvidas, a influência dos laços sociais na escolha e na coordenação das alianças, entre outros.

Para fechar esse fórum especial sobre alianças estratégicas e redes de alianças, Rodrigo Medeiros Feijó e Rovian Dill Zuquetto retomam um caso já estudado em 2004: a rede de lojas de material de construção Redemac. Os autores se propõem a examinar a formação, o desenvolvimento, os benefícios e os resultados desta rede de cooperação no artigo "Cooperar para Sobreviver e Crescer - Análise da Rede de Cooperação Redemac". Os resultados deste estudo de caso reforçam achados anteriores que apontaram os benefícios das trocas de informações, dos ganhos em escala e da redução de custos proporcionados pela rede aos seus associados. Não obstante, o artigo também avança ao estabelecer uma comparação entre as perspectivas das lojas antes e depois da associação à rede.

É imprescindível agradecer o convite da Revista de Administração Mackenzie para compor este grupo de editores do fórum especial em alianças e redes de alianças. Igualmente, faz-se necessário agradecer à comunidade acadêmica, que acolheu esta iniciativa e, especialmente, aos autores que submeteram seus artigos à apreciação deste fórum. Agradeço também a todos os pareceristas que dedicaram seu tempo a avaliar com asseio e minúcia cada manuscrito recebido. Os seis artigos publicados evidentemente não esgotam o rico cenário da produção acadêmica brasileira sobre a cooperação em alianças e redes, mas representam a materialização de esforços de pesquisa que têm sido realizados em centros e grupos de estudos de norte a sul do país. Espera-se que as contribuições já destacadas e as demais que serão encontradas nos artigos desta edição sejam também convites à reflexão e ao posicionamento crítico que poderão originar e oxigenar o desenvolvimento de novos estudos sobre o tema, e que esses estudos motivem uma nova edição especial daqui a dez anos.

Boa leitura! 
JORGE VERSCHOORE

Editor convidado

Doutor em Administração pelo Programa de Pós-Graduação em Administração da Universidade Federal do Rio Grande do Sul (UFRGS). Professor e pesquisador do Programa de Pós-Graduação em Administração da Universidade do Vale do Rio dos Sinos (Unisinos).

E-mail: jorgevf@unisinos.br

SERGIO BULGACOV

Editor convidado

Doutor em Administração de Empresas pela Escola de Administração de Empresas de São Paulo da Fundação Getulio Vargas (EAESP-FGV). Professor e pesquisador do Programa de Pós-Graduação em Administração da Escola de Administração de Empresas de São Paulo da Fundação Getulio Vargas.

E-mail: s.bulgacov@gmail.com

ANDRÉA PAULA SEGATTO Editora convidada

Doutora em Administração pela Faculdade de Economia, Administração e Contabilidade da Universidade de São Paulo (FEA-USP). Professora e pesquisadora do Programa de Pós-Graduação em Administração da Universidade Federal do Paraná (UFPR). E-mail:aps@ufpr.br

WALTER BATAGLIA Editor convidado

Doutor em Administração pela Faculdade de Economia, Administração e Contabilidade da Universidade de São Paulo (FEA-USP). Professor e pesquisador do Programa de Pós-Graduação em Administração da Universidade Presbiteriana Mackenzie (UPM).

E-mail: batagliaw@gmail.com

\section{REFERÊNCIAS}

Balestrin, A., \& Vargas, L. M. (2004). A dimensão estratégica das redes horizontais de PMEs: teorizações e evidências. Revista de Administração Contemporânea, 8(Edição Especial), 203-227.

Balestrin, A., Verschoore, J. R., \& Reyes, E., Jr. (20I0). O campo de estudo sobre redes de cooperação interorganizacional no Brasil. Revista de Administração Contemporânea, 14(3), 459-477.

Balestro, M. V., Antunes, J. A. V., Júnior, Lopes, M. C., \& Pellegrin, I. D. (2004). A experiência da Rede Petro-RS: uma estratégia para o desenvolvimento das capacidades dinâmicas. Revista de Administração Contemporânea, 8(Edição Especial), I8I-202. 
Böhe, D. M., \& Silva, K. M. (2004). O dilema de crescimento em redes de cooperação: o caso da Panimel. In J. R. Verschoore. Redes de cooperação: uma nova organização de pequenas e médias empresas no Rio Grande do Sul (pp. I57-I8I). Porto Alegre: Fundação de Economia e Estatística.

Borgatti, S. P., \& Foster, P. C. (2003). The network paradigm in organizational research: a review and typology. Journal of Management, 29(6), 99I-IOI3.

Cropper, S., Ebers, M., Huxham, C., \& Ring, P. S. (20I4). Handbook de relações interorganizacionais da Oxford. Porto Alegre: Bookman.

Kushima, A., \& Bulgacov, S. (2006). Estratégia e relações em arranjos produtivos e seus efeitos sobre as cadeias de valores: o consórcio de Maringá e o projeto setorial integrado de Apucarana. Organizações \& Sociedade, 13(37), 87-I07.

Laniado, R. N., \& Baiardi, A. (2003). A contribuição das redes na formação da cooperação empresarial - um estudo de caso. Organizações \& Sociedade, 10(27), 6I-74.

Lazzarini, S. G., \& Joaquim, T. A. Z. (2004). A formação de constelações: o caso da indústria global de transporte aéreo. RAE - Revista de Administração de Empresas, 44(2), II-25.

Lopes, F. D., \& Baldi, M. (2005). Laços sociais e formação de arranjos organizacionais cooperativos: proposição de um modelo de análise. Revista de Administração Contemporânea, 9(2), 8I-IOI.

Macadar, B. M. (2004). A experiência exportadora da associação dos fabricantes de estofados e móveis complementares. In J. R. Verschoore. Redes de cooperação: uma nova organização de pequenas e médias empresas no Rio Grande do Sul (pp. I83-I99). Porto Alegre: Fundação de Economia e Estatística.

Machado-da-Silva, C. L., \& Coser, C. (2006). Rede de relações interorganizacionais no campo organizacional de Videira, SC. Revista de Administração Contemporânea, 10(4), 9-45.

Pereira, B. A. D., \& Pedrozo, E. A. (2005). Contribuições à consolidação da teoria estratégica interorganizacional: uma análise dos relacionamentos horizontais. Revista de Administração Contemporânea, 9(4), I4I-I6I.

Pereira, R. C. F. (2004). Marketing em redes de cooperação: um estudo de caso na Redemac. In J. R. Verschoore. Redes de cooperação: uma nova organização de pequenas e médias empresas no Rio Grande do Sul (pp. 20I-224). Porto Alegre: Fundação de Economia e Estatística.

Sacomano Neto, M., \& Truzzi, O. M. S. (2004). Configurações estruturais e relacionais da rede de fornecedores: uma resenha compreensiva. Revista de Administração da Universidade de São Paulo, 39(3), 255-263.

Segatto-Mendes, A. P., \& Mendes, N. (2006). Cooperação tecnológica universidade-empresa para eficiência energética: um estudo de caso. Revista de Administração Contemporânea, 10(Edição Especial), 53-75.

Segatto-Mendes, A. P., \& Rocha, K. C. (2005). Contribuições da teoria de agência ao estudo dos processos de cooperação tecnológica universidade-empresa. Revista de Administração da Universidade de São Paulo, 40(2), I72-183.

Tauhata, T. L., \& Macedo-Soares, T. D. L. V. A. (2004). Redes e alianças estratégicas no Brasil: caso CVRD. RAE-Eletrônica, 3(I), I-23.

Verschoore, J. R. (2004a). Redes de cooperação: uma nova organização de pequenas e médias empresas no Rio Grande do Sul. Porto Alegre: Fundação de Economia e Estatística.

Verschoore, J. R. (2004b). Redes de cooperação: concepções teóricas e verificações empíricas. In J. R. Verschoore. Redes de cooperação: uma nova organização de pequenas e médias empresas no Rio Grande do Sul (pp. I5-46). Porto Alegre: Fundação de Economia e Estatística. 